\title{
TRANSMUTAÇÃO: ANCESTRALIDADE NA POÉTICA DE BNEGÃO
}

\author{
TransmutAção: ancestry in BNegão's poetic
}

\author{
Ellen Berezoschi \\ https://orcid.org/0000-0002-0923-4220 \\ Universidade Federal de Santa Catarina, Programa de Pós-Graduação em Literatura, \\ Florianópolis, SC, Brasil. 88040-900 - ppglitufsc@gmail.com
}

\begin{abstract}
Resumo: Este artigo pretende analisar três canções do disco TransmutAção, do rapper BNegão, em conjunto com o grupo Seletores de Frequência. A análise tem como centralidade uma performance específica dos artistas, feita no Centro Cultural Vila Verde, em São Paulo, em 2015, na qual ancestralidade e ritmo marcam os ensinamentos do tempo e demarcam a dádiva do momento presente. A análise tem como principal fundamento as ideias de Paul Zumthor por evidenciar, principalmente, questões relativas à performance e como essa se constitui. $\mathrm{O}$ texto ainda abrange a noção de performance por seu caráter ritualístico que envolve espiritualidade (neste caso, pelo conteúdo da mensagem de Bnegão) e por seu caráter poético-musical que realiza uma invocação do momento presente, priorizando o aqui e o agora dos integrantes do ato poético. $\mathrm{O}$ artigo explora a performance como um todo, analisando a música, a poesia, o gesto e a constituição do acontecimento. Em alguns momentos, ainda, o disco é citado como um todo, enquanto obra, por carregar uma mensagem que atravessa todas as canções.
\end{abstract}

Palavras-chave: Performance. Temporalidade. Ritmo.

Abstract: This article intends to analyze three songs from the album TransmutAção, by rapper Bnegão, together with the group Seletores de Frequência. The analysis focuses on a specific performance of the artists, made at the Centro Cultural Vila Verde, in São Paulo, in 2015, in which ancestry and rhythm mark the teachings of time and mark the gift of the present moment. The analysis is based mainly on the ideas of Paul Zumthor, as it highlights issues related to performance and how it is constituted. The text also covers the notion of performance due to its ritualistic character that involves spirituality (in this case, the content of Bnegão's message) and its poetic-musical character that makes an invocation of the present moment, which prioritizes the here and now of the members of the poetic act. The article explores performance as a whole, analyzing music, poetry, gesture and the constitution of the event. In some moments, the album is also mentioned as a whole, as a work, for carrying a message that crosses all the songs.

Keywords: Performance. Temporality. Rhythm.

\section{Introdução}

A poesia, de maneira geral, antes do domínio maior da escrita, sempre teve como centralidade a voz e a performance, ou seja, é na poesia que se percebe aquilo que compete não

Esta obra está licenciada sob uma Creative Commons - Atribuição 4.0 
só às palavras, mas à toda uma forma de linguagem que transcende a língua. É na voz que se percebe a presença de um corpo e seus afetos e é na performance que se percebem os gestos desse corpo e toda a sua carga poética não dizível. Com o avanço de um modo de vida mais individualista, mais raros são os rituais em que a voz é o agente principal do ato poético, assim como é raro o próprio ato poético em si. A vida resume-se a apreciar as artes de maneira individual e, no caso da poesia, através dos livros, ou das mídias digitais, quando se trata de oralidade. E o rito, sacro ou não, torna-se mais obsoleto quando tratamos da palavra poética. Sobre os ritos, é possível ler em Performance, recepção e leitura que:

A maior parte das definições de performance põe ênfase na natureza do meio, oral e gestual. Segundo Hymes, destaco a emergência, a reiterabilidade, o reconhecimento, que englobo sob o termo ritual. A "poesia" (se entendemos por isto o que há de permanente no fenômeno que para nós tomou a forma de "literatura") repousa, em última análise, em um fato de ritualização da linguagem. Daí uma convergência profunda entre performance e poesia, na medida em que ambas aspiram à qualidade de rito. Utilizo aqui esta última palavra despojando-a de toda conotação sacra. Entre um "ritual" no sentido religioso estrito e um poema oral poderíamos avançar, dizendo que a diferença é apenas de presença ou ausência do sagrado. No entanto, a experiência que tenho das culturas nas quais subsistem tradições orais vivas, leva-me a pensar que essa diferença não é percebida por aqueles partícipes dessas culturas. No caso do ritual propriamente dito, incontestavelmente, um discurso poético é pronunciado, mas esse discurso se dirige, talvez, por intermédio dos participantes do rito, aos poderes sagrados que regem a vida; no caso da poesia, o discurso se dirige à comunidade humana: diferença de finalidade, de destinatário; mas não da própria natureza discursiva. É verdade que, historicamente, o discurso ritual tem a tendência de perdurar em sua forma, de ser menos acessível que o discurso não sacro aos fenômenos de movência e de variação. (ZUMTHOR, 2002, p. 45).

A música, de certa forma, sempre teve uma característica de ritualização da linguagem que se dirige "à comunidade humana". Um show, mesmo que esteja servindo à indústria do entretenimento, tem sua dimensão ritualística, invocando a presença daqueles que proferem seu discurso e seus ritmos e daqueles que participam do momento como destinatários ou receptores. É quando a poesia se mostra como presença, no corpo de todos que constroem o momento presente. Esse artigo é sobre as conexões da voz com a ancestralidade, a voz que precisa sair, o som preso na garganta e o momento poético da performance, na qual gesto e voz marcam o ponto de transmutação entre o passado, o presente e o futuro, na presença do aqui e do agora.

Neste artigo, será feita a análise de uma performance ao vivo, acessada pelo Youtube de uma apresentação do disco TransmutAção, de BNegão (2015) e dos Seletores de Frequência. E por mais que neste caso, estaremos investigando uma performance mediatizada, - que acaba por ser despersonalizada pela sua reiterabilidade, ou seja, não se pode responder às performances mediatizadas (ZUMTHOR, 1997) - porém, mesmo assim, é possível aguçar os nossos sentidos e perceber traços dessa obra poética que transcende a escrita, através dos ritmos, do som e da voz. A palavra ritualística de BNegão, combinada com a poesia da sonoridade serão o tom e o timbre para enriquecer os estudos da poesia oral, incorporando os estudos de 
Paul Zumthor $(1997,2002)$ como base fundamental.

Para isso, terei como objeto principal a canção "Nós (Ponto de mutação)", mas, para que exista uma compreensão do leitor sobre a mensagem desse disco, esboçarei uma curta análise sobre algumas outras canções do disco, para que a análise seja satisfatória, de acordo com os termos de performance, definidos por Paul Zumthor (1997) em seu profundo estudo sobre a poesia oral. Trabalharei com a performance ao vivo do disco, de um show apresentado por BNegão \& Seletores de Frequência, no Centro Cultural Rio Verde (SP) em 13 de dezembro de 2015 - neste show, até os 45 minutos e 30 segundos é tocado o disco TransmutAção, após isso, os músicos passam a tocar diversas músicas de outros discos que, por mais que expressem mensagens muito parecidas, não serão abordadas neste trabalho.

Em 2015, BNegão \& Seletores de Frequência lançam o disco TransmutAção que, entre outras coisas, apresenta uma poesia que invoca a espiritualidade por seu caráter ritualístico. Explorando a percussão dos tambores e agogôs, o sopro dos metais e as rimas de BNegão (2015), o disco é um convite a um rito poético e musical, que fala de ensinamentos, de ancestralidade e do cotidiano, que muitas vezes bloqueia os contatos sensoriais entre os seres. $\mathrm{O}$ disco pode ainda ser lido como uma homenagem ao próprio ritual e à performance em si, por lembrar-nos do momento presente, da importância de sentir, da poesia que nos move a partir dos sentidos e dessa trajetória da oralidade no seu sentido mais amplo, do dizível e do não dizível.

\section{Dias da serpente}

O show inicia com a introdução "Agò”, com os tambores de Alexandre Garnizé e com a voz de um dos integrantes da banda cantando a palavra "Agò" que, de acordo com a religião da Umbanda é um pedido de licença, de permissão ou benção para o que se está fazendo - ou seja, pede-se permissão para o ritual acontecer, para abrir os caminhos e para trazer todos ao presente. A introdução já é combinada com a primeira canção do disco e do show "Dias da Serpente", que, após os cumprimentos de BNegão (2015), dando "boa noite", inicia com os seguintes versos:

Aqui estamos, nesse planeta, nesse momento, estamos

O que construímos e o que desconstruímos até aqui, estamos

O que somos, o que achamos que somos

Células, ossos, carne, sangue, cromossomos

Espíritos, que se movem, agora e sempre

Realidades, dimensões, agora e sempre ${ }^{1}$ (BNEGÃO, 2015, n.p).

No show, os versos são seguidos de BNegão (2015) dizendo: "São Paulo, bem vindos à transmutação". Os versos, ao longo de toda a canção, são pronunciados por BNegão (2015) sempre com os olhos fechados, como um início de um ritual, para que as energias estejam concentradas na presença, no aqui e no agora. Traz o corpo para a presença, com suas células,

\footnotetext{
${ }^{1}$ São minhas esta e as demais transcrições dos versos de BNegão (2015).
} 
sua carne, seu sangue e seus cromossomos - estes já dão um indicativo da memória ancestral do corpo - além dos espíritos e das realidades e dimensões que não podem ser vistas, mas que estão presentes e que são sentidas. "Meu corpo é a materialização daquilo que me é próprio, realidade vivida e que determina minha relação com o mundo" (ZUMTHOR, 2002, p. 23) são as palavras de Paul Zumthor (2002) sobre a presença do corpo e aqui, podemos trazer um destaque para a palavra "relação" utilizada pelo autor. Para tanto, tomo a liberdade de invocar a ideia de Relação, elaborada por Édouard Glissant (2011). Para Glissant (2011), a Relação é aquilo que permite a crioulização entre as culturas. A Relação é o que surge a partir do contato colonial da Plantation; desde o navio negreiro, os negros escravizados eram separados de suas famílias e etnias, propositalmente, para que a comunicação entre eles não fosse possível devido às barreiras linguísticas. E já na diáspora, esse contato aconteceu de várias formas, crioulizando culturas e línguas. É na Relação que o eu se borra com o outro. A Relação é, portanto um conceito que carrega uma história de ancestralidade, marcada pela violência colonial. $\mathrm{O}$ disco de BNegão (2015) faz uma saudação a essa ancestralidade através do ritual da música. É o aqui e agora em que "estamos" como convoca BNegão (2015) para esse ritual de transmutação. Retomaremos à Relação mais adiante quando entrarmos na análise da canção "Nós", tema central deste trabalho.

Essa convocação para estar presente, no aqui e no agora, está profundamente associada não só com rituais espirituais, mas com a ideia de performance em si, que convida os receptores a estarem presentes no ato poético performatizado e que possui essa conexão ancestral com a transmissão das mensagens, como ocorria, por exemplo, com os griots africanos. Paul Zumthor (1997) possui um profundo estudo sobre a poesia oral e sobre a performance poética. Ele diz:

Performance implica competência. Além de um saber-fazer e de um saberdizer, a performance manifesta um saber-ser no tempo e no espaço. O que quer que, por meios linguísticos, o texto dito ou cantado evoque, a performance lhe impõe um referente global que é da ordem do corpo. É pelo corpo que nós somos tempo e lugar: a voz o proclama emanação do nosso ser. A escrita também, comporta, é verdade, medidas de tempo e espaço: mas seu objetivo último é delas se liberar. A voz aceita beatificamente sua servidão. A partir desse sim primordial, tudo se colore na língua, nada mais nela é neutro, as palavras escorrem, carregadas de intenções, de odores, elas cheiram ao homem e à terra (ou aquilo com que o homem os representa). A poesia não mais se liga às categorias do fazer, mas às do processo: o objeto a ser fabricado não basta mais, trata-se de suscitar um sujeito outro, externo, observando e julgando aquele que age aqui e agora. É por isso que a performance é também instância de simbolização: de integração de nossa relatividade corporal na harmonia cósmica significada pela voz; de integração da multiplicidade das trocas semânticas da unicidade de uma presença. (ZUMTHOR, 1997, p 157, grifos no original).

"Agò" e "Dias da Serpente" são a transmissão da ideia de um "saber-ser no tempo e no espaço", o corpo é invocado a estar presente e, através da voz, combinada com os ritmos e os sons, ele emana os seres envolvidos nessa performance. O show de BNegão (2015) emana os seres, físicos e espirituais que constroem em conjunto o ato poético, sendo tempo e lugar ao 
mesmo tempo: sendo presença. Essa é a mensagem, principal do disco; a transmutação, invocada tanto ao longo de todo o disco é esse estar aqui e agora, invocando e interagindo com o passado e com o futuro. "O que construímos e o que desconstruímos até aqui, estamos" (BNEGÃO, 2015, n.p); nos versos, esse "estar" é justamente a integração da relatividade corporal em harmonia cósmica, significada pela voz - estamos, no momento presente, com toda a história do passado e com todas as surpresas do futuro; estamos com o corpo em harmonia com o cosmos, essa unidade da totalidade universal. Estar presente, aqui e agora, é estar em harmonia com o cosmos, em comunhão do um com o com os outros. Zumthor (2002) coloca a performance no lugar do sensorial, daquilo que os sentidos percebem nesse contato com o outro. As trocas entre o eu e o outro se harmonizam a partir dos sentidos e da linguagem poética que nos entrelaça. O cosmos é o que dá a dimensão entre o eu e o todo. É a troca entre o universal e o particular, entre o particular e o universal, transcendendo as dimensões de tempo e espaço.

\author{
Enxergar amplamente, enxergar além \\ É vital para a sobrevivência da sua mente \\ Transmutação é a palavra chave \\ Dias luminosos virão \\ Dias trevosos estão \\ Dias da serpente \\ Preso no passado, com saudade do futuro \\ Ausente \\ Longe do presente (BNEGÃO, 2015, n.p).
}

A serpente simboliza tanto o começo quanto o fim, ela devora sua própria cauda, ela representa o passado que um dia retorna, o "efeito boomerang", como BNegão (2003) traz em outra canção de outro disco ${ }^{2}$. A serpente aqui representa o tempo, que cobra de nós aquilo que plantamos para depois colher, convivendo com diferentes tempos num mesmo corpo. É a simbologia da circularidade das coisas e da vida. Por isso, a importância de transmutar, para não estar mais "preso no passado" e nem "com saudade do futuro". A transmutação é o ato de saudar aqueles que foram antes de nós e, ao mesmo tempo, deixar o passado para trás, se libertar do que as outras gerações carregaram de dores e dificuldades. É o ato de respeitar a imprevisibilidade do futuro, entendendo que as ações geram reações ${ }^{3}$ e que o que se faz no presente, é o que dita o que virá. A transmutação é a compreensão de que o presente é a única coisa que temos de concreto e que, vive-lo de forma plena e harmoniosa, é como podemos lidar com o passado e com o futuro.

\title{
No ar (convocação)
}

A ideia da transmutação que percorre todo o disco fica muito evidente também na canção "No ar (convocação)", que como o próprio título expressa, convoca os ancestrais como fonte de sabedoria do tempo, como geração após geração, o presente é uma dádiva e é sempre uma

\footnotetext{
2 Aqui me refiro à canção "Vai e volta" presente no disco "Enxugando o gelo" (2003), em que a ideia é ressaltar como as coisas que vêm, voltam e que tudo o que se faz na vida possui consequências.

${ }^{3}$ A temática de ação e reação é trabalhada também no disco "Sintoniza lá" (2012), com a canção "Reação".
} 
possibilidade de mudança, de transformação. E a performance oferece essa possibilidade de transformação a partir da interação. De acordo com Paul Zumthor (2002),

Não é menos verdade, no entanto, que toda leitura seja produtividade e que ela gere um prazer. Mas é preciso reintegrar, nesta idéia de produtividade, a percepção do conjunto de percepções sensoriais. A recepção, eu o repito, se produz em circunstância psíquica privilegiada: performance ou leitura. É então e tão-somente que o sujeito, ouvinte ou leitor, encontra a obra; e a encontra de maneira indizivelmente pessoal. Essa consideração deixa formalmente íntegra a teoria alemã da recepção, mas lhe acrescenta uma dimensão que lhe modifica o alcance e o sentido. Ela a aproxima, de algum modo, da ideia de catarse, proposta (em um contexto totalmente diferente) por Aristóteles. Comunicar (não importa o quê: com mais forte razão um texto literário) não consiste somente em fazer passar uma informação; é tentar mudar aquele a quem se dirige; receber uma comunicação é necessariamente sofrer uma transformação. (ZUMTHOR, 2002, p. 52).

Esse encontro entre a obra e o leitor ou ouvinte é o que permite a transformação daquele que lê ou interage com o ato poético. Essa transformação só pode acontecer, justamente porque essa recepção é, acima de tudo, sensorial e está no campo da percepção das coisas. A informação, aquilo que é dito transcende a língua e atinge o outro naquilo que não é dito, mas sentido e vivido. Importante ainda é destacar o que Zumthor (2002) nos coloca sobre esse encontro do leitor com a obra, que é indizivelmente pessoal; de novo, o universal e o particular se intercalam e, em uma performance ou em um ritual poético, existe a experiência coletiva de compartilhar o momento presente com os demais que fazem parte do ato - e a experiência individual - aquilo que marca cada sujeito dentro da sua particularidade e individualidade.

Aquilo que está no ar, que não pode ser visto e apenas sentido ou vivido é o que BNegão nos convoca a sentir e viver, através dos tambores bem marcados e de um momento ritualizado. Na performance do Centro Cultural Rio Verde, BNegão (2015) inicia essa canção dizendo "quem tiver na disposição de bater uma palma de samba de terreiro, é agora hein?" (2015) e assim, integrantes dos Seletores de Frequência começam as palmas de terreiro, oficializando o momento presente como um ritual espiritual, no qual a sacralidade se mistura com o momento mundano do encontro musical. Ao longo da performance o som cresce, ocupando espaço, e dando "a certeza da presença", em ambos os sentidos, material e espiritual. Ele canta:

Em movimentos circulares expanda

A energia da mudança em todos os lugares

Dança

Nessa ciranda de dimensões interconectadas

Presente, passado, futuro

Costumo achar o que eu procuro

Futuro, presente, passado

Acredite, tem sempre um guia do seu lado

Passado, futuro e presente

Passado, futuro e presente

$\mathrm{Mizifi}^{4}$, acredite no que vê

4 “Mizifi" significa “meu filho" nas celebrações de Umbanda. 
Mas, mais ainda no que sente (BNEGÃO, 2015, n.p).

Bnegão (2015) traz nos versos a importância de sentir, de perceber as coisas a partir dos mecanismos sensoriais, em que o ver é importante, mas sentir é fundamental, é o que transforma. Essa transformação é a mudança, são os movimentos circulares, são as cirandas interconectadas, é a dança, é a música. A música sempre esteve presente em boa parte dos rituais religiosos e também dos não religiosos. Paul Zumthor (2002) traz diversos exemplos, nos seus estudos antropológicos, da presença da música em comunhão com o ato poético e de como ambas, poesia e música, se misturam. E, muitas vezes, nem faz sentido separá-las, já que o acontecimento do rito se constitui de diversas faces.

Os rituais sagrados das sociedades sempre tiveram a música e o ritmo como aquilo que marca o momento, o fundamento das relações. O som, o silêncio, os ruídos e as músicas são o que demarcam as relações sociais em determinadas civilizações.

Nos rituais que constituem as práticas da música modal invoca-se o universo para que seja cosmos e não-caos. Mas, de todo modo, os sons afinados pela cultura, que fazem a música, estarão sempre dialogando com o ruído, a instabilidade, a dissonância. Aliás, uma das graças da música é justamente essa: juntar, num tecido muito fino e intrincado, padrões de recorrência e constância com acidentes que os desequilibram e instabilizam. Sendo sucessiva e simultânea (os sons acontecem um depois do outro, mas também juntos), a música é capaz de ritmar a repetição e a diferença, o mesmo e o diverso, o contínuo e o descontínuo. Desiguais e pulsantes, os sons nos remetem no seu vai-e-vem ao mesmo tempo sucessivo e linear mas também a um outro tempo ausente, virtual, espiral, circular ou informe, e em todo caso não cronológico, que sugere um contraponto entre o tempo da consciência e o não-tempo do inconsciente. Mexendo nessas dimensões, a música não refere nem nomeia coisas visíveis, como a linguagem verbal faz, mas aponta com uma força toda sua para o não-verbalizável; atravessa certas redes defensivas que a consciência e a linguagem cristalizada opõem à sua ação e toca em pontos de ligação efetivos do mental e do corporal, do intelectual e do afetivo. Por isso mesmo é capaz de provocar as mais apaixonadas adesões e as mais violentas recusas. (WISNIK, 1989, p. 27-28).

Os estudos de Wisnik (1989) sobre o som e o sentido nos dão essa dimensão da música constituída pelo movimento de nossos corpos, pelo não-verbalizável, aquilo que tem a força do inconsciente - e, para pensar nos termos de BNegão (2015), por que não subconsciente? - em que o tempo não é linear, ele é apenas ritmo e som. E existe ruído no som, existe caos no som, por mais que se tente ordená-lo. Mesmo a dança, que pode ter passos fixados, nunca está livre do caos, do improviso, daquilo que sai da forma e que deixa o campo aberto para a construção imediata. $\mathrm{O}$ ato imediato do presente está sempre expondo o jogo do ritmo e o jogo do tempo.

Talvez, uma das maiores lições do disco de BNegão (2015) é o ensinamento do tempo, de que estamos apenas de passagem ${ }^{5}$ (2003) e que aquilo que temos de fato é o momento presente. A performance nos chama para o presente, para sentir o nosso corpo, para estar em

${ }^{5} \mathrm{~A}$ ideia de que estamos nesse mundo apenas de passagem é muito exposta por Bnegão na canção "Prioridades", do disco "Enxugando o gelo" (2003). 
contato com nós mesmos a partir do contato com o outro. Aquilo que temos é a Relação da qual Glissant (2011) fala, é a possibilidade de surgir novas culturas a partir dos contatos poéticos das identidades rizoma ${ }^{6}$.

\section{Nós (ponto de mutação)}

O disco todo tem como proposta a ideia da transmutação, ou seja, da comunhão temporal da ancestralidade, como a principal sabedoria do presente. E a canção "Nós (ponto de mutação)", apresenta a necessidade e o "dever de todos" de desatar os nós do pensamento e os nós da garganta. Quando se percebe a necessidade de desatar os nós da garganta, é possível agregar algumas reflexões em torno disso.

A primeira que apresento aqui, talvez a mais breve, tem relação com as referências espirituais do Oriente apresentadas ao longo da canção. BNegão (2015) se aproxima dos ensinamentos da ioga (quando pronuncia "namastê") e dos chakras (quando relembra Dalai Lama). É possível refletir como um convite ao ouvinte ou espectador a abrir o $3^{\circ}$ chackra, que é localizado na região da garganta, como um processo de limpeza, em que é urgente fazer a voz ecoar.

A segunda reflexão tem a ver com a história do ocidente, das vozes oprimidas e caladas pela escravidão. A ancestralidade do ocidente é a história da colonização e da plantation - lugar em que os negros escravizados faziam ecoar seus cantos de lamento e elaboravam um nova comunicação a partir dos cantos e ritmos afinal, não conseguiam se comunicar apenas através da fala, pois desde o embarque no navio negreiro, eram separados de suas etnias e colocados com outros sujeitos de etnias diferentes. Essa mistura de culturas possibilitou novas formas de sociabilidade, através da música, esse grito oprimido que a colonização fez perdurar.

Essa ideia da voz oprimida, mas que resistiu, foi apresentada anteriormente quando tratei da Relação, conceito de Édouard Glissant (2011). Foi apenas a partir do contato musical e poético que as vozes oprimidas pelo sistema colonial começaram a emergir das senzalas e das plantações. A partir dessas vozes e desses corpos inscritos num ambiente de violência é que surgem as culturas mais fortes das Américas, as culturas de origem negra africana. Essas origens são quase impossíveis de serem rastreadas por completo, mas o que vemos presente é a ancestralidade do ritmo.

Novamente, a performance é bem marcada pelos tambores. Nota-se o jogo com a palavra "nós", que no início representava os nós que precisam ser desatados, ou seja, aquilo que incomoda, que precisa ser desfeito e, então, BNegão (2015) deseja luz para todos nós, substituindo o substantivo pelo pronome "nós" e enfatizando que "nós somos um". Por isso o "nós" é o ponto de mutação, a mudança que ocorre da relação entre o eu e o outro, no qual as fronteiras se desfazem e o que sobra é o momento presente da interação. $\mathrm{O}$ ensinamento de BNegão (2015), tem a ver com a ideia de performance de Zumthor (2002):

\footnotetext{
${ }^{6}$ Édouard Glissant (2011) utiliza o conceito de rizoma elaborado por Deleuze e Guattari para falar das identidades e dessa forma, a identidade passa a ser algo aberto que possui vários rizomas e não apenas uma raiz.
} 
Termo antropológico e não histórico, relativo, por um lado, às condições de expressão, e da percepção, por outro, performance designa um ato de comunicação como tal; refere-se a um momento tomado como presente. A palavra significa a presença concreta de participantes implicados nesse ato de maneira imediata. Nesse sentido, não é falso dizer que a performance existe fora da duração. Ela atualiza virtualidades mais ou menos numerosas, sentidas com maior ou menor clareza. Elas as faz "passar ao ato" fora de toda consideração pelo tempo. (ZUMTHOR, 2002, p. 50, grifos no original).

E esse "imediato" é o momento em que o "nós" é possível, ou seja, em que toda a sabedoria dos que já foram se faz presente, naquela interação, naquele instante e o que fica para o futuro são as mudanças que a performance proporciona, coletivas ou individuais. Por isso, a performance ocorre também fora da duração afinal, cada sujeito presente nesse espetáculo proporcionado por BNegão (2015) e pelos Seletores de Frequência leva consigo a mudança da interação, leva o momento coletivo dentro de si e a marca daquele acontecimento no seu corpo.

BNegão coloca "nós" num sentido tão amplo e coletivo que aproveita o ritual estabelecido entre artistas e público para saudar aqueles que o inspiraram e que também fizeram parte da história coletiva de todos nós. Ele canta:

Agora um salve
A todos os mestres
Todos os mestres que fizeram esse processo
No grau máximo
E fazem, alguns ainda
Mahatma Gandhi
Martin Luther king
Milton Santos
Darcy Ribeiro
Professor Hermógenes
Dalai Lama
Matheus Aleluia
Triguerinho
Tom Zé
Yoga Nanda
Aos mestres, revolucionários
Jardineiros da sabedoria e da esperança
A eles, minha gratidão
Seguimos, São Paulo (BNEGÃO, 2015, n.p).

Na versão do disco, BNegão (2015) ainda os chama de "mestres da mutação", trazendo a ideia de revolução e de mudança. É interessante destacar que o movimento, após a saudação e o agradecimento aos mestres, BNegão (2015) diz "seguimos", mostrando novamente o tempo como um caminhar, como um movimento eterno, no qual levamos os ensinamentos, mas nos desprendemos do passado. O movimento, a movência - pensando nos termos de Zumthor (2002) -, tem como característica fundamental a atualização dos textos (escritos ou não) e dos ensinamentos passados. Bnegão (2015) oferece essa visita ao passado, justamente para que possamos seguir mais fortes e compreendendo que nós, também somos mutação, podemos ser jardineiros da sabedoria e da esperança. O artista está sempre jogando com o tempo, mostrando 
todas as conexões entre passado, presente e futuro.

\section{Referências}

BNegão \& Seletores de Frequência. Enxugando o gelo. 2003. Disponível em: https://www.youtube.com/watch?v=TTDX3LtqVXE. Acesso em: 19 ago. 2020.

BNegão \& Seletores de Frequência. Sintoniza lá. 2012). Disponível em: https://www.youtube.com/watch?v=f9rQI7jR6No\&list=PL65XOkgJXJ8xFyUyYf1Oi4jXAbl 9Xil9C Acesso em: 19 ago. 2020.

BNegão \& Seletores de Frequência no Centro Cultural Rio Verde - Apresentação na íntegra. [S.1.: s.n.], 2015. 1 vídeo (ca. 1:49:40). Publicado pelo canal Showlivre. Disponível em: https://www.youtube.com/watch?v=MO3HppVkcXU\&t=2684s. Acesso em: 19 ago. 2020.

GLISSANT, Édouard. Poética da Relação. Trad. de Manuela Mendonça. Porto: Porto Ed, 2011.

WISNIK, José Miguel. O som e o sentido. São Paulo: Companhia das Letras, 1989.

ZUMTHOR, Paul. Introdução à poesia oral. Trad. de Jerusa Pires Ferreira, Maria Lúcia Diniz Pochat, Maria Inês de Almeida. São Paulo: Editora Huitec, 1997.

ZUMTHOR, Paul. Performance, recepção e leitura. Trad. de Jerusa Pires Ferreira e Suely Fenerich. São Paulo: Cosac Naify, 2002.

\section{NOTAS DE AUTORIA}

Ellen Berezoschi (ellen.berezoschi@gmail.com) é Bolsista FAPESC de Doutorado pelo Programa de Pós-Graduação em Literatura da Universidade Federal de Santa Catarina. É mestra em Literatura pelo mesmo Programa. Estuda rap, oralidade e performance, bem como assuntos relacionados à diáspora africana e os impactos culturais percebidos a partir do processo colonial.

\section{Como citar esse artigo de acordo com as normas da revista}

BEREZOSCHI, Ellen. "TransmutAção": ancestralidade na poética de BNegão. Anuário de Literatura, Florianópolis, v. 25, n. 2, p. 161-171, 2020.

\section{Contribuição de autoria}

Não se aplica.

Financiamento

Fundação de Amparo à Pesquisa e Inovação de Santa Catarina - FAPESC.

\section{Consentimento de uso de imagem}

Não se aplica.

Aprovação de comitê de ética em pesquisa

Não se aplica. 


\section{Licença de uso}

Este artigo está licenciado sob a Licença Creative Commons CC-BY. Com essa licença você pode compartilhar, adaptar, criar para qualquer fim, desde que atribua a autoria da obra.

\section{Histórico}

Recebido em: 01/06/2020

Aprovado em: 14/08/2020 